\title{
A Comparative Study Between Conventional and Direct Stenting by Measuring Serum Cardiac Troponin-I
}

\author{
SYEDAFAHMIDAAFRIN ${ }^{1}$, MD. HASANUR RAHMAN ${ }^{2}$, SYED DAWOOD MD. TAIMUR $^{2}$,MUHSINAABDULLAH ${ }^{3}$, \\ SAFIA SHARMIN ${ }^{4}$, ESMAT ARA $^{5}$ \\ ${ }^{1}$ Department of Biochemistry,Ibn sina Medical College \& Hospital, ${ }^{2}$ Department of Cardiology, Ibrahim Cardiac Hospital and \\ Research Institute, ${ }^{3}$ Savar Upozilla Health Centre, ${ }^{4}$ Department of Biochemistry, Holy Family Medical College \& Hospital, \\ ${ }^{5}$ Department of Biochemistry, Eastern Medical College \& Hospital.
}

Address for Correspondence: Syeda Fahmida Afrin, Department. of Biochemistry, Ibn Sina Medical College \& Hospital. Email: fahmidahasanur@gmail.com

\begin{abstract}
The aim of the study is to assess serum Cardiac Troponin-I level in patients who have underdone Percutaneous coronary intervention (PCI) as an indication of myocardial injury and. Compare the troponin-I level in direct or conventional stetting in PCI and assess the superiorty of two methods of PCI, regarding myocardial injury and outcome. Cardiac Troponin-I (cTnI) is known to have the highest specificity \& analytic sensitivity for detection of myocardial injury. This study was aimed to compare between conventional and direct stenting by assessing of serum cTnI. This observentional study was carried out in the Deparment of Biochemistry, Dhaka Medical College \& Dept. of Cardiology, Ibrahim Cardiac Hospital and Research Institute during the period from July 2007 to June 2008. In this study we enrolled 60 diagnosed cases of coronary heart disease patients which were grouped as direct stenting (30 patients) and conventional stenting (30 patients) group. In this study, the age of the patients ranged from 42-72 years with a mean of $56.7( \pm 7.1)$ years. Male and female participants were 44 and 16 respectively. The mean left ventricular ejection fraction of them were $55.43( \pm 7.9)$ $\%$. The difference of the mean troponin-I level before direct and conventional stenting was similar. Although the mean level of troponin-I after conventional stenting was higher $(0.081 \pm 0.042)$ than that of direct stenting (0.066 \pm 0.042$)$, the difference of means was not statically significant $(P>0.05)$. Significant difference was observed between the mean before and after direct stenting as well as conventional stenting. From our observation we can conclude that serum cTnI level was higher after conventional stenting than that of direct stenting but the difference of means was not statically significant. It rises significantly after Percutaneous coronary intervention regardless of the type of procedure, whether direct or conventional stenting. Though the clinical outcome is reported to be similar in direct and conventional stenting, the direct stenting requires less procedural and equipment cost as well as less exposure time to radiation.
\end{abstract}

Key wards : Conventional stenting; Direct stenting; Troponin-I.

\section{Introduction}

Coronary artery disease (CAD) is a chronic disease in which blood flow is obstructed through the coronary arteries that supply the heart with oxygen-rich blood. A disease known as atherosclerosis, which is sometimes called "hardening of the arteries", causes this obstruction. An estimated 13.2 million Americans suffer from CAD. ${ }^{1}$ Percutaneous coronary intervention (PCI), commonly known as coronary angioplasty or simply angioplasty, is a therapeutic procedure to treat the stenotic (narrowed) coronary arteries of the heart found in coronary heart disease. These stenotic segments are due to the build up of cholesterol-laden plaques that form due to atherosclerosis. ${ }^{2}$ Percutaneous coronary intervention (PCI) uses a flexible plastic catheter with a balloon at the end to dilate narrowed arteries in the heart. The procedure often includes placement of a metal stent to hold the artery open. ${ }^{3}$ Angioplasty is performed mainly by two processes: the standard or conventional stent implantation technique involves predilatation of the target lesion with a balloon catheter to allow easy passage of the stent and to assess the likelihood of complete stent expansion after deployment. On the other way, direct stenting involves stenting without balloon predilatation. Concerning this procedural modification of stent implantation in direct stenting technique; several studies have been performed to compare the conventional \& direct stenting technique. The direct coronary stenting (DISCO) trial and TRENDS (Tetra Randomized European Direct Stenting Study) have shown that the direct stenting is technically feasible in majority of patients yielding similar angiographic outcomes as the standard conventional technique, But less duration of procedure, less resource utilization, less radiation exposure and trend towards less major adverse cardiac event (MACE) rate are prevalent in case of direct stenting. ${ }^{4}$ The standard 
coronary stent implantation technique, although universally used, usually requires the use of a balloon and has the potential for dissections and/or other complications such as abrupt vessel closure, elastic recoil, suboptimal injury minor myocardial injury (MMI), probably resulting from the longer ischemic duration, side branch occlusion and distal embolization as described earlier. ${ }^{5}$ Currently, more than $20 \%$ of the elective coronary stenting is performed without predilatation. ${ }^{6}$ The extensive use of stents in the treatment of coronary artery disease led cardiologists to simplify the procedure by introducing the concept of stenting without predilatation, i.e., direct stenting. Several studies conformed the safety and feasibility of the procedure to rates greater than $90 \% .{ }^{7}$ Cardiac troponin is sensitive and specific markers for the detection of minor myocardial injury. ${ }^{8}$ Cardiac troponin-I (cTnI) is a protein marker specific for cardiac muscle with a molecular weight of 23000. Together with troponin $\mathrm{T}$ and $\mathrm{C}$, it forms a structural complex. There are two forms of cTnI, free cTnI and cTnI I-T-C complex, which are released in blood stream after cardiac damage. ${ }^{9}$ We have known for many decades that diabetes increases the risk of cardiovascular (CV) disease. About 65\% of deaths in individuals with diabetes are related to heart disease or stroke. An exceptionally high risk has been observed among patients with diabetes after they suffer their first CV event; for example, myocardial infarction. ${ }^{10}$ The purpose of the study was to measure cardiac troponin-I (cTnI) level after elective uncomplicated successful percutaneous transluminal coronary angioplasty (PTCA) with or without stenting in diabetic patients.

\section{Subjects and methods :}

The present study was observational study carried out in the Department of Biochemistry, Dhaka Medical College \& Dept. of Cardiology, Ibrahim Cardiac Hospital and Research Institute during the period from July 2007 to June 2008. In study, we conveniently enrolled 60 consecutive patients with known case of coronary artery disease diagnosed angiographically and recommended for PCI \& who are both clinically and haemodynamically stable with no evidence of acute ischemia or infarction and grouped as direct stenting (30 patients) and conventional stenting (30 patients) group. In this study, one hour before PCI sample of blood was collected to measure the pre PCI serum troponin-I level. Then after successful PCI another sample of blood was collected 6 hours post PCI to see the troponin-I level. With all aseptic precautions, $2 \mathrm{ml}$ of venous blood was collected from the anterior cubital vein of every patient with coronary artery disease. The blood sample was immediately transferred to a dry clean glass test tube and allowed to clot. The sample was then centrifuged and serum was collected in a test tube, labeled appropriately and preserved at $2^{\circ}-8^{\circ} \mathrm{C}$ until used for assay of troponin-I in autoanalyzer.

\section{Inclusion criteria:}

- Diabetic coronary patients aged $>18$ years diagnosed angiographically and recommended for PCI.

- Patients who are both clinically and haemodynamically stable with no dynamic ECG changes with any evidence acute ischemia or infarction.

\section{Exclusion Criteria:}

- $\quad$ Patients undergoing primary PCI

- $\quad$ Patients undergoing facilitated or rescue PCI.

- $\quad$ Patients with haemodynamic and clinical instability with dynamic ECG changes before PCI.

\section{Statistical analysis :}

Data were expressed as mean \pm SD unless otherwise stated. Statistical analysis was performed by SPSS software version 12. . Data were expressed as frequency, percentage and mean ( \pm SD). Confidence level was fixed at 95\% level and 'p' value of 0.05 or less was considered significant. Paired't' test was done for quantitative (continuous) variables before and after intervention.

\section{Results}

In this study, the age of the patients ranged from 42-72 years with a mean of $56.7( \pm 7.1)$ years. Out of 60 patients 30 (50\%) were selected for direct stenting and another 30 (50\%) were selected for conventional stenting.

The mean $( \pm S D)$ of troponin-I levels of the patients before undergoing direct and conventional stenting was 0.028 $( \pm 0.0144)$ and $0.034( \pm 0.0147) \mathrm{ng} / \mathrm{ml}$ respectively. The difference of means between troponin-I levels before direct and conventional stenting was not significant ( $\mathrm{p}>0.05)$. The mean $( \pm \mathrm{SD})$ of troponin-I levels of the patients after performing direct and conventional stenting was 0.066 $( \pm 0.042)$ and $0.081( \pm 0.042) \mathrm{ng} / \mathrm{ml}$ respectively. The difference of means between troponin-I levels after direct and conventional stenting was not significant ( $\mathrm{p}>0.05$ ). The difference of means between troponin-I levels before and after undergoing direct stenting was significant $(p<0.05)$. The difference of means between troponin-I levels before and after doing conventional stenting was significant $(\mathrm{p}<0.05)$. [Table-I] 
Table-I

Distribution of age of the patients

\begin{tabular}{lccccrr}
\hline Distribution of age & $\mathrm{N}$ & Range & Minimum & Maximum & \multicolumn{2}{c}{ Mean \pm SD } \\
\hline Age of the patients & Total & 60 & 30 & 42.00 & 72.00 & $56.73 \pm 7.12$ \\
& Male & 44 & 30 & 42.00 & 72.00 & $56.41 \pm 7.44$ \\
& Female & 16 & 21 & 45.00 & 66.00 & $57.63 \pm 6.31$ \\
\hline
\end{tabular}

Distribution of sex of the patients

Among the participants 44(73.3\%) were male and 16(26.7\%) were female.

\begin{tabular}{lcc}
\hline Sex (in Number) & Group-I $(\mathrm{n}=30)$ & Group-II $(\mathrm{n}=30)$ \\
\hline Male & 21 & 23 \\
Female & 9 & 7 \\
\hline
\end{tabular}

Distribution of left ventricular ejection fraction (\%):

The mean $( \pm S D)$ left ventricular ejection fraction of total, male and female patients were $55.43( \pm 7.9), 55.25( \pm 8.02)$ and 55.94( \pm 7.79$) \%$ respectively.

Table-III

Descriptive Statistics of left ventricular ejection fraction (\%)

\begin{tabular}{lccccc}
\hline Left ventricular ejection fraction (\%) & N & Minimum & Maximum & Mean & Std. Deviation \\
\hline Total & 60 & 40.00 & 70.00 & 55.43 & 7.90 \\
Male & 44 & 40.00 & 70.00 & 55.25 & 8.03 \\
Female & 16 & 40.00 & 70.00 & 55.94 & 7.79 \\
\hline
\end{tabular}

Table-IV

Comparison of serum cardiac troponin-I level $(\mathrm{ng} / \mathrm{ml})$ between direct and conventional stenting before and after intervention

\begin{tabular}{|c|c|c|c|c|}
\hline \multicolumn{2}{|l|}{ Type of intervention } & \multicolumn{2}{|c|}{ Mean \pm SD of Troponin-I t value } & \multirow{2}{*}{$\frac{\text { p value }}{0.162^{\mathrm{NS}}}$} \\
\hline Before stenting & $\operatorname{Direct}(n=30)$ & $0.028 \pm 0.014$ & -1.418 & \\
\hline & Conventional $(n=30)$ & $0.034 \pm 0.015$ & & \\
\hline \multirow[t]{2}{*}{ After stenting } & $\operatorname{Direct}(n=30)$ & $0.066 \pm 0.042$ & -1.343 & $0.185^{\mathrm{NS}}$ \\
\hline & Conventional $(n=30)$ & $0.081 \pm 0.042$ & & \\
\hline \multirow[t]{2}{*}{ Direct stenting } & Before $(n=30)$ & $0.028 \pm 0.014$ & -4.553 & $0.000 *$ \\
\hline & After $(n=30)$ & $0.066 \pm 0.042$ & & \\
\hline \multirow[t]{2}{*}{ Conventional stenting } & Before $(n=30)$ & $0.034 \pm 0.015$ & -5.916 & $0.000 *$ \\
\hline & After(n=30) & $0.081 \pm 0.042$ & & \\
\hline
\end{tabular}

NS= Not significant,$*$ Significant, $\mathrm{n}=$ number of subject

Table-V

Descriptive Statistics of Level of troponin-I $(\mathrm{ng} / \mathrm{ml})$ before and after intervention

\begin{tabular}{|c|c|c|c|c|c|c|}
\hline \multicolumn{2}{|c|}{ Level of troponin-I (ng/ml) } & \multirow{2}{*}{$\frac{N}{60}$} & \multirow{2}{*}{$\frac{\text { Minimum }}{.01}$} & \multirow{2}{*}{$\frac{\text { Maximum }}{.06}$} & \multirow{2}{*}{$\frac{\text { Mean }}{.031}$} & \multirow{2}{*}{$\frac{\text { Std. Deviation }}{.0147}$} \\
\hline Before intervention & Total & & & & & \\
\hline Male & 44 & .01 & .06 & .030 & .0143 & \\
\hline Female & 16 & .01 & .06 & .033 & .0158 & \\
\hline After intervention & Total & 60 & .010 & .160 & .073 & .0425 \\
\hline Male & 44 & .010 & .160 & .079 & .0456 & \\
\hline Female & 16 & .020 & .120 & .057 & .0273 & \\
\hline
\end{tabular}




\section{Discussion}

The present observentional study was carried out to assess and compare the serum troponin-I level before and after conventional as well as direct stenting in patients with coronary heart disease and diabetes mellitus. From the knowledge gathered by reviewing related literature we assumed that troponin-I increase after percutaneous coronary intervention due to minor myocardial injury in diabetic patients.

The mean $( \pm \mathrm{SD})$ of troponin-I levels of the patients before undergoing direct and conventional stenting was 0.028 $( \pm 0.0144)$ and $0.034( \pm 0.0147) \mathrm{ng} / \mathrm{ml}$ respectively. The difference of means was not statistically significant ( $p>0.05$ ). We measured the baseline cTn-I of all patients, which was important to differentiate the release of troponin owing to pre-existing cardiac disease, and its release after PCI related cardiac injury. Babuin and Jaffe described in a review that elevated level of basal troponin-I have prognostic importance. They noted that elevation of troponin-I level more than 25\% of baseline should be considered due to the procedure. ${ }^{11}$ The mean $( \pm \mathrm{SD})$ of troponin-I levels of the patients after performing direct and conventional stenting was $0.066( \pm 0.042)$ and $0.081( \pm 0.042) \mathrm{ng} / \mathrm{ml}$ respectively. Although the mean troponin-I level after intervention was higher in conventional stenting (CS group) group than direct stenting (DS group) group, the difference of means could not reach the statistically significant level ( $p>0.05)$. This finding is in agreement with the finding of Tinurkynak. They carried out the study among 60 patients with mean age of $57.1( \pm 10.4)$ years. Of these 60 patients 37 underwent direct stenting and 23 underwent conventional stenting. They also found cardiac troponin-T (cTnT) to be higher in the CS group than in the DS group at 16 hours postprocedure, but these values did not reach statistical significance $(p>0.05)$. They concluded that direct stenting was not proven to be better than conventional stenting regarding myocardial injury. Hoffman indirectly supported our findings. They demonstrated that direct stenting in human atherosclerotic coronary vessels results in similar vessel trauma compared with conventional stenting. This finding may indicate that release of cTn-I from traumatized vessel is similar in both direct stenting and stenting after predilatation. They also concluded that direct stenting offers comparable immediate and follow-up clinical, angiographic, and intravascular ultrasound results than conventional stenting at lower resource utilization. ${ }^{12}$ The mean $( \pm S D)$ of troponin-I levels of the patients before and after undergoing direct stenting was $0.028( \pm 0.0144)$ and $0.066( \pm 0.0421) \mathrm{ng} / \mathrm{ml}$ respectively. There was significant difference between the means $(\mathrm{p}<0.05)$. Our findings are consistent with a report by Barbato, Marco and Wijns. They stated in a review article that direct stenting in acute coronary syndromes (ACS) has been associated with significant improvement in ST-segment resolution and reduction in post procedural increase in Tn-I. They also advocated that direct stenting had positive impact on procedure duration, cost, radiation exposure time, and amount of contrast dye used. ${ }^{13}$ The mean $( \pm S D)$ of troponin-I levels of the patients before and after undergoing conventional stenting was $0.034( \pm 0.0147)$ and $0.081( \pm 0.0423) \mathrm{ng} / \mathrm{ml}$ respectively. The difference of means was significant $(\mathrm{p}<0.05)$. The mean $( \pm \mathrm{SD})$ of troponin-I levels of the total patients before and after doing intervention was $0.031( \pm 0.0147)$ and $0.073( \pm 0.0425) \mathrm{ng} / \mathrm{ml}$ respectively.

The result of our study suggests that troponin-I similarly rises in both direct and conventional stenting indicating similar myocardial injury in both the groups. However, the data available so far support the concept that direct stenting is both feasible and safe. The procedural outcome seems to be superior in the absence of pre-dilatation due to a reduced incidence of dissections at the stent edges. Although dissections are unlikely to be completely avoided during direct stenting, it is conceivable that dissections are sealed by stent deployment at the moment they are created. Another major advantage of direct stenting could be the reduction of distal embolization during PCI on thrombus containing lesions. Though the clinical outcome seems to be equivalent in direct and conventional stenting, the direct stenting requires less procedural and equipment cost as well as less exposure time to radiation.

Study Limitation: Due to constraint of fund, we could not measure some important tests related to our research. Our limitations of this study are the small number of patients in each group because of time limitation.

\section{Conclusion:}

From our observation we can conclude that serum cTnI level was higher after conventional stenting than that of direct stenting but the difference of means was not statically significant. Though the clinical outcome is reported to be similar in direct and conventional stenting, the direct stenting requires less procedural and equipment cost as well as less exposure time to radiation.

\section{References:}

1. Anonymous. Coronary Artery Disease. (2003). Available at: http://yourtotalhealth. zivillage.com/coronary-arterydisease.html. [Access on 10 ${ }^{\text {th }}$ May 2008]. 
1. Anonymous. Coronary Artery Disease. (2003). Available at: http://yourtotalhealth. zivillage.com/coronary-arterydisease.html. [Access on 10 ${ }^{\text {th }}$ May 2008].

2. Wikipedia. The free encyclopedia. Percutaneous coronary intervention. (2007) Available at: http://en.wikipedia.org/wiki/ Percutaneous_coronary _ intervention.

3. Aroesty, J.M. Percutaneous coronary intervention. (2008) Available at: http://www.uptodate.com/patients/content/ topic.do?topicKey=hrt_dis/5829[Access on $5^{\text {th }}$ May 2008].

4. Gruberg, L. Tetra Randomized European Direct Stenting Study.(2002). Available at: File://E:\TRENDS\% 20Tetra\% Randomized\% 20\%European\% 20Direct\% 20Stenting\% 20Study. [Access on $12^{\text {th }}$ May 2008].

5. Fischman, D.L., Leon, M.B., Beim, D.S. A randomized comparison of coronary- stent placement and balloon angioplasty in the treatment of coronary artery disease. Stent Restenosis Study Investigators. N Engl J Med 1994; 331: 496-501.

6. Richards, A.M., McDonald, D., Fitzpatrick, M.A. Atrial natriuretic hormone has biological effects in man at physiological plasma concentrations. Cln Endocrinol Metab 1998; 67: 1134-39.
7. Clarkson, P.B., Wheeldon, N.M., McLeod, C., Cutie, W., MacDonald, T.M. Brain natriuretic peptide: effect on left Ventricular filling patterns in healthy subjects. Clin Sci (Colch) 1995; 88: 159-64.

8. Saadeddin, S.M., Habbab M.A., Sobki, S.H., Ferns, G.A. Minor myocardial injury after elective uncomplicated successful PTCA with or without stenting: Detection by cardiac troponins. ISSN 2001; 53(2): 188-92.

9. Erza, A., Amsterdam, Deedwana, P. Bedside evaluation of cardiac marker. Postgraguate Medicine 2005; 118: 3.

10. Milicevic, Z., Raz Itamar, Campaigne, B.N., Beattie, S.D., Campaigne, B.N., Sarwat, S. Natural history of Cardiovascular Disease in patients with Diabetes. Diabetes Care 2008; 31:155160 .

11. Babuin, L., Jaffe, A.S. Troponin: the biomarker of choice for the detection of cardiac injury. CMAJ 2005; 173(10): 19112007.

12. Hoffman. A Randomized comparison of Clopidogrel and Aspirin. Am Heart J 2004; 147(4): 15.

13. Barbato, E., Marco, J., Wijns, W. (2003). Direct stenting. European Heart Journal 2003; 24(5): 394-340. 